\title{
AS REPRESENTAÇÕES INDÍGENAS NOS LIVROS: A TERRA DOS MIL POVOS - HISTÓRIA INDÍGENA DO BRASIL CONTADA POR UM ÍNDIO, DE KAKÁ WERÁ JECUPÉ, E IRACEMA, DE JOSÉ DE ALENCAR
}

\author{
THE INDIGENOUS REPRESENTATION ON BOOKS: \\ A TERRA DOS MIL POVOS - HISTÓRIA INDÍGENA DO \\ BRASIL CONTADA POR UM ÍNDIO, BY KAKÁ WERÁ \\ JECUPÉ, AND IRACEMA, BY JOSÉ DE ALENCAR \\ Camyla Aparecida Mello Ferreira* \\ Fábio Augusto Steyer
}

Resumo: O presente artigo é o resultado das reflexões, discussões e pesquisas realizadas na disciplina de Literatura, história e identidade do programa de Pós-graduação do Mestrado em Estudos da Linguagem, da Universidade Estadual de Ponta Grossa. Assim, tendo por objetivo refletir sobre como as identidades indígenas são construídas nos textos A terra dos mil povos - História Indígena do Brasil contada por um índio, de Kaká Werá Jecupé, e Iracema, de José de Alencar. Existem diversas discussões sobre a literatura indígena no Brasil, e esse trabalho busca delinear como são constituídas as identidades indígenas na visão dos dois autores, com a presente análise pode-se afirmar que Alencar, em sua literatura indianista, constrói o indígena pelo olhar do branco; já Jecupé nos apresenta a identidade indígena de seu lugar de fala, trazendo consigo toda a história de um povo.

Palavras-chave: literatura indígena; literatura brasileira; identidade.

Aвstract: The present article is the result from reflections, discussions and research made in the Literature, history and identity course of the Master's degree program in Language Studies, from the Universidade Estadual de Ponta Grossa. Having as an objective to reflect on how the indigenous identities are built in the texts A terra dos mil povos - História indígena do Brasil contada por índio, by Kaká Werá Jecupé, and Iracema,

\footnotetext{
"Mestranda do Programa de Pós-Graduação em Estudos da Linguagem da Universidade Estadual de Ponta Grossa (UEPG). E-mail: camy-mello@hotmail.com.

"* Pós-Doutor em Letras pela UFRGS, professor do Departamento de Estudos da Linguagem da Universidade Estadual de Ponta Grossa (UEPG). E-mail: fsteyer@uol.com.br.
} 
by José de Alencar. A lot is discussed about indigenous literature in Brazil, and this work seeks to outline how the indigenous identities are built in both authors' vision, Alencar on his Indianist literature builds the indigenous through the eyes of the white; whereas Jecupé presents us the indigenous identity from his place of speech, bringing alongside him all the history of his people.

KEYwoRDs: indigenous literature; Brazilian literature; identity.

\section{INTRODUÇão}

O artigo é resultado das leituras, discussões, reflexões e análises realizadas na disciplina de Literatura, história e identidade do programa de Pós-graduação do Mestrado em Estudos da Linguagem, da Universidade Estadual de Ponta Grossa (UEPG).

Durante minha graduação em Letras Português/Inglês, pela UEPG, desenvolvi estudos, pesquisas e participei de projetos relacionados ao campo da linguística, pois é uma área que muito me interessa. Mas, a partir do momento em que comecei a trabalhar como professora, a minha percepção da educação começou a mudar e comecei a perceber algumas atitudes que desencadearam diversos questionamentos sobre a educação brasileira.

O interesse pela literatura indígena teve início quando participei, como professora, de uma Equipe Multidisciplinar em uma escola estadual da rede de ensino do estado do Paraná.

Considero importante definir o que são as Equipes Multidisciplinares. Elas foram criadas no estado do Paraná e:

são instâncias de organização do trabalho escolar, preferencialmente coordenadas pela equipe pedagógica, e instituída por Instrução da SUED/SEED de acordo com o disposto no art. 8.o da Deliberação No 04/06 - CEE/PR, com a finalidade de orientar e auxiliar o desenvolvimento das ações relativas à Educação das Relações Étnico-Raciais e ao Ensino de História e Cultura Afro-Brasileira, Africana e Indígena, ao longo do período letivo e;

- que Equipes Multidisciplinares se constituem por meio da articulação das disciplinas da base nacional comum, em consonância com as Diretrizes Curriculares Estaduais da Educação Básica e Diretrizes Curriculares Nacionais para a Educação das Relações Etnicorraciais e para o Ensino de História e Cultura Afrobrasileira e Africana, com vistas a tratar da História e Cultura da África, dos Africanos, Afrodescendentes e Indígenas no Brasil, na perspectiva de contribuir para que o/a aluno/a negro/a e indígena mire-se positivamente, pela valorização da história de seu povo, da cultura, da contribuição para o país e para a humanidade (PARANÁ, 2010). 
Para os profissionais que fazem parte dessas equipes, é ofertado um curso, com duração de um ano. Nesse curso são disponibilizados textos e vídeos sobre a história e cultura africana, afro-brasileira e indígena, que servem como suporte teórico para o desenvolvimento de atividades e projetos na escola. Nesse ambiente também estão disponíveis questões relacionadas aos textos teóricos, que servem como avaliação para obtenção do certificado do curso.

A Equipe Multidisciplinar da qual eu fazia parte realizava a leitura dos textos disponibilizados, que depois eram discutidos em um encontro presencial e, por fim, realizávamos as atividades que eram propostas no ambiente virtual. A proposta do curso é que, com os materiais disponibilizados, os professores propusessem projetos nas aulas de suas disciplinas sobre a história e cultura africana, afro-brasileira e indígena, no decorrer do ano letivo.

Com base nos estudos realizados na Equipe Multidisciplinar, notei durante o curso que, como professora de literatura do Ensino Médio, não tinha conhecimentos sobre a literatura indígena, e a partir desse momento pesquisei sobre a literatura indígena, buscando referenciais teóricos para elaborar o projeto a ser aplicado em sala de aula.

Após a pesquisa, propus a realização de um projeto nas turmas em que lecionava, organizando a proposta da seguinte forma: Os alunos seriam divididos em seis grupos, deveriam pesquisar autores indígenas e cada grupo leria um livro de literatura indígena; os alunos apresentariam a obra para os colegas e fariam uma análise dela. Para minha surpresa, eles relataram que na biblioteca não havia livros de literatura indígena. Então, precisei adaptar minha proposta e os alunos apresentaram os autores indígenas que encontraram em sites na internet.

A partir desse momento, percebi que a escola em que trabalhava não tinha em sua biblioteca exemplares de livros de literatura indígena e também observei que no livro didático adotado pela escola não havia uma menção a essa literatura. Esses fatos fizeram com que eu procurasse na internet por livros, autores e informações sobre a produção de literatura indígena no Brasil, o que foi muito difícil.

A ausência de referenciais sobre a temática foi um dos motivos que me levaram a ingressar no mestrado em Estudos da Linguagem, da Universidade Estadual de Ponta Grossa, pois precisava buscar referenciais sobre o assunto. Seguindo nesta direção, minha pesquisa tem por objetivo abordar a literatura indígena no currículo escolar. Para aprofundar as minhas leituras optei por cursar a disciplina Literatura, História e Identidade, e o presente trabalho é o artigo final da citada disciplina.

Partindo da experiência relatada e das inquietações decorrentes das discussões ao longo da disciplina, surgiu o seguinte questionamento que norteia a presente pesquisa: como o indígena é retratado no livro A terra dos mil povos: História indígena do Brasil contada por um indio, de Kaka Werá Jecupé? E como o indígena era representado na literatura indianista no livro Iracema, de José de Alencar? O objetivo é comparar as duas obras e identificar as representações das identidades indígenas em cada uma delas. 
A presente pesquisa é de cunho qualitativo e utiliza o método de análise documental. Segundo Lüdke e André (1986, p. 38), "a análise documental pode se constituir numa técnica valiosa de abordagem de dados qualitativos, seja complementando as informações obtidas por outras técnicas, seja desvelando aspectos novos de um tema ou problema". Devido a esse aspecto, a pesquisa documental é o método adequado para a presente pesquisa.

Ainda, segundo os autores, são documentos: "leis e regulamentos, normas, pareceres, cartas, memorandos, diários pessoais, autobiografias, jornais, revistas, discursos, roteiros de programas de rádio e televisão até livros, estatísticas e arquivos escolares" (LÜDKE, ANDRÉ, 1986, p. 38). Para a análise dos documentos foi utilizada a análise de conteúdo, proposta por Bardin (1977). De acordo com o autor, essa análise se refere a:

Um conjunto de técnicas de análises das comunicações visando obter, por procedimentos, sistemáticos e objetivos de descrição do conteúdo das mensagens, indicadores (quantitativos ou não) que permitam a inferência de conhecimentos relativos às condições de produção/recepção (variáveis inferidas) destas mensagens (BARDIN, 1977, p. 42).

Partindo desse pressuposto, foram selecionados os textos teóricos e os literários para compor o corpus da pesquisa. Em seguida, foram realizadas as leituras dos textos selecionados. Os textos literários escolhidos para a análise foram: A terra dos mil povos: História indígena do Brasil contada por um índio, de Kaká Werá Jecupé, e Iracema, de José de Alencar.

Antes da análise dos textos literários, é imprescindível que façamos um breve percurso histórico da literatura e, também, conhecer a lei que tornou obrigatório o ensino de história e cultura afro-brasileira e indígena nas escolas brasileiras.

Como ponto de partida da presente pesquisa, ressaltamos que a literatura indígena começou a ter uma maior visibilidade no Brasil a partir da promulgação e implementação da lei 11.645/08 que alterou a lei 10.639/03, incluindo a obrigatoriedade do ensino de história e cultura indígena. A redação da lei, que anteriormente abrangia a história e cultura africana e afro-brasileira, passou a ser a seguinte:

Art. $1^{\circ} \mathrm{O}$ art. 26-A da Lei $\mathrm{n}^{\circ}$ 9.394, de 20 de dezembro de 1996, passa a vigorar com a seguinte redação:

Art. 26-A. Nos estabelecimentos de ensino fundamental e de ensino médio, públicos e privados, torna-se obrigatório o estudo da história e cultura afro-brasileira e indígena.

$\$ 1^{\circ}$ O conteúdo programático a que se refere este artigo incluirá diversos aspectos da história e da cultura que caracterizam a formação da população brasileira, a partir desses dois grupos étnicos, tais como o estudo da história da África e dos africanos, a luta dos negros e dos povos indígenas no Brasil, a cultura negra e indígena brasileira e o negro 
e o índio na formação da sociedade nacional, resgatando as suas contribuições nas áreas social, econômica e política, pertinentes à história do Brasil.

$\$ 2^{\circ}$ Os conteúdos referentes à história e cultura afro-brasileira e dos povos indígenas brasileiros serão ministrados no âmbito de todo o currículo escolar, em especial nas áreas de educação artística e de literatura e história brasileiras. (NR)

Art. $2^{\circ}$ Esta Lei entra em vigor na data de sua publicação (BRASIL, 2008).

Esse fato é um importante marco para a educação e, principalmente, para o ensino de literatura, pois, desde então, a literatura indígena deve ser abordada no Ensino Fundamental e no Ensino Médio, tanto na rede pública, como na rede particular. Isso significa incorporar autores e textos marginalizados, ou seja, que estavam à margem do ensino de literatura, eles não faziam parte do cânone brasileiro até então.

\section{LITERATURA BRASILEIRA: UM PERCURSO HISTÓRICO}

Para compreender o momento histórico em que cada livro analisado foi produzido, é importante fazermos um breve percurso histórico da literatura brasileira.

A literatura brasileira sofreu diversas transformações no decorrer de sua história, tendo seu início por volta de 1800 , pois é nesse período em que se começa a pensar em uma literatura nacional. Porque, até então, segundo Magalhães (1836, p. 6):

A poesia brasileira não é uma indígena civilizada; é uma grega vestida à francesa e à portuguesa, e climatizada no Brasil; é uma virgem do Hélicon que, peregrinando pelo mundo, estragou seu manto, talhado pelas mãos de Homero, e sentada à sombra das palmeiras da América, se apraz ainda com as reminiscências da pátria, cuida ouvir o doce murmúrio da castalha, o trépido sussurro do Lodon e do Ismeno, e toma por um rouxinol o sabiá que gorjeia entre os galhos da laranjeira. Enfeitiçados por esse nume sedutor, por essa bela estrangeira, os poetas brasileiros se deixaram levar por seus cânticos, e olvidaram a simples imagem que uma natureza virgem com tanta profusão lhes oferecia. Semelhante à Armida de Tasso, cuja beleza, artifícios e doces palavras atraíram e desorientaram os principais guerreiros do exército cristão de Gofredo. É rica a mitologia, são belíssimas as suas ficções, mas à força de serem repetidas e copiadas vão sensivelmente desmerecendo; além de que, como o pássaro da fábula, despimos nossas plumas para nos apavonar com velhas galas, que nos não pertencem. 
Em síntese, para Domingos José Gonçalves de Magalhães (1836), a literatura produzida desde o descobrimento do Brasil é uma mescla de influências das mais diferentes produções literárias mundiais com o ambiente brasileiro, em que, na realidade, o autor produz seu texto nos mesmos moldes de grandes obras já existentes, utilizando como cenário o Brasil, suas paisagens e seus sujeitos.

Em meados de 1800, Gonçalves de Magalhães (1836) e José de Alencar (1856) publicaram textos críticos sobre o que seria uma literatura genuinamente brasileira. Nesse período, havia a preocupação em criar uma identidade nacional, pois esse movimento estava ocorrendo após a Independência do Brasil e havia a necessidade de uma identificação com o que seria um espírito nacional. José de Alencar escreveu cartas sobre a obra A Confederação dos Tamoios, de Gonçalves de Magalhães, criticando a forma com que o autor a escreveu, como ele descreve os lugares. Na primeira carta, critica a forma como descreve exaustivamente o Amazonas e a falta de descrição sobre o Paraná:

No trecho sobre o Amazonas há alguns versos lindíssimos, algumas imagens muito felizes, mas é bastante longo; o poeta parece ter esgotado n'elle ioda a sua inspiração, que fez-lhe falta na descripção do Paraná. A pintura da vida dos índios não tem, na minha opinião, a menor belleza; uma página de um viajante qualquer a respeito da vida nômade dos Árabes do deserto é mais cheia dessa poesia da liberdade selvagem do que a parte do poema a que me refiro (ALENCAR, 1856, p. 8)1.

A crítica de Alencar também aborda a questão da personagem feminina na obra que, segundo ele, seria uma mulher que poderia estar presente "em um romance árabe, chinês ou europeu" (ALENCAR, 1856, p. 31), que era apenas uma mulher chamada "Iguassú". Nesse sentido, Alencar entende que Magalhães não consegue fazer uma poesia nacional, representar o povo brasileiro.

Em seus textos críticos, Magalhães aborda a questão da criação de uma literatura nacional que, segundo ele, só surgiu três séculos depois do descobrimento do Brasil:

Do que fica dito, podemos concluir que o país se não opõe a uma poesia original, antes a inspira. Se até hoje a nossa poesia não oferece um caráter inteiramente novo e particular, é porque os nossos poetas, dominados pelos preceitos, limitaram a imitar os antigos que, segundo diz Pope, é imitar mesmo a natureza, como se a natureza se ostentasse em todas as regiões e, diversos sendo os costumes, as religiões e as crenças, só a poesia não pudesse participar dessa atividade, dessa variedade, nem devesse exprimi-la (MAGALHÃES, 1836, p. 10).

${ }^{1} \mathrm{O}$ trecho da carta de José de Alencar foi mantido com a redação original. Devido a isso a ortografia é diferente da atual ortografia da língua portuguesa. 
Conforme o autor, os poetas, para serem considerados bons, deveriam criar e não imitar os moldes clássicos existentes, e também afirma que os indígenas conservam uma tradição literária oral que deveria influenciar e inspirar os poetas brasileiros.

Os autores que criticavam as imitações literárias que os outros publicavam não conseguiam, na prática, desvincular-se dos moldes e influências europeias. Eles tentaram construir uma literatura nacional utilizando as referências indígenas, os cenários brasileiros, mas não conseguiram se desvencilhar do que já estava posto na literatura mundial, por exemplo, a figura do indígena nas obras.

Com o passar do tempo, foi-se constituindo o cânone da literatura brasileira, e nessa construção muitas obras e autores não tiveram espaço. A partir da promulgação da Constituição Federal de 1988, a literatura indígena começou a ganhar espaço tanto no mercado editorial quanto no ambiente educacional. Houve uma sequência de leis que foram promulgadas e contribuíram para que a literatura indígena ocupasse seu lugar na literatura brasileira.

Em 2003, a promulgação da lei 10.639/03 tornou obrigatório o ensino de História e Cultura Afro-Brasileira em todas as instituições de ensino fundamental e médio, privadas e públicas. Em seguida, no ano de 2008, foi promulgada a lei 11.645/08, que alterou a redação da lei 10.639/03, incluindo junto ao ensino da história e cultura afro-brasileira o ensino da história e cultura indígena.

Com essas mudanças na lei, houve a necessidade, por parte das editoras, de buscarem materiais dessas culturas para compor seus livros. Acredito, assim como Brandes (2017, p. 9), que:

Nos últimos anos a literatura indígena vem ganhando espaço no Brasil. As editoras têm publicado cada vez mais livros de escritores indígenas e, embora em número pequeno [...]. Um grande passo pra que a literatura indígena ganhasse espaço foi a implantação de lei 11.645/08, comentada acima.

A lei foi uma grande conquista para os povos indígenas, que durante muito tempo vinham lutando para que suas culturas e histórias fizessem parte do currículo escolar. Com a lei, em todas as escolas do país, Histórias e Culturas Africana, afro-brasileiras e Indígenas são conteúdo obrigatório, embora nem sempre sejam de fato trabalhados, muitas vezes por falta de formação dos professores.

Concordando com Brandes (2017), percebo que já houve uma mudança em relação ao ensino da literatura indígena, mas é necessário discutir, ainda, sobre o que é a literatura indígena, como o autor indígena representa sua identidade, se essa representação é feita da mesma forma que o homem branco o descreveu em diversos textos. É partindo dessa necessidade que serão analisados os romances escolhidos para este trabalho. 
As REPRESENTAÇõES INDÍGENAS NOS LIVROS: A TERRA DOS MIL POVOS - HISTÓRIA INDÍGENA DO BRASIL CONTADA POR UM ÍNDIO, DE KAKÁ WERÁ JECUPÉ, E IRACEMA, DE JOSÉ DE ALENCAR

\section{LITERATURA INDÍGENA E LITERATURA INDIANISTA}

Para a análise das obras literárias escolhidas, é necessário distinguir literatura indígena e literatura indianista. Nesse tópico, proponho-me a fazer essa distinção para que, a partir dela, se realize a análise das identidades indígenas construídas pelos autores em suas obras.

É importante destacar a diferença entre literatura indígena e indianista. Como Julie Dorrico (2018, p. 231-232, grifos do autor) afirma, “a diferença da literatura indígena brasileira contemporânea em relação à literatura indianista encontra-se, sobretudo, na autoria e na representação realizadas por autores não indígenas". Ainda, nesse texto, a autora traz as definições que Romero faz sobre literatura indígena e indianista:

A literatura indianista é criada por escritores não indígenas que afirmam ser porta-vozes dessa cultura.

Literatura indigenista: os escritores também não são indígenas, mas procuram entrar nesse pensamento a partir de sua perspectiva, tentam penetrar em sua cosmologia para divulgar essa cultura.

Literatura indígena é a produção escrita pelos próprios indígenas em seu idioma original ou em uma versão bilíngue. Pode abranger todos os gêneros: poesia, narrativa, teatro e ensaio (ROMERO apud DORRICO, 2018, p. 232, tradução nossa). ${ }^{2}$

É a partir das definições acima descritas que analisarei as obras selecionadas. Para tanto, foram escolhidos apenas dois trechos, um de cada obra, para poder realizar a análise.

\section{ANÁliSE DAS OBRAS IRACEMA, DE JOSÉ DE ALENCAR, E A TERRA DOS MIL POVOS: HISTÓRIA INDÍGENA DO BRASIL CONTADA POR UM ÍNDIO, DE KAKA WERÁ JECUPÉ}

primeiramente, é necessário situar a produção de Alencar no século XIX, em que havia uma necessidade de criação de identidade nacional e sua produção ficcional auxilia nessa construção. Segundo Menezes (2013, p. 183):

Alencar acalenta um propósito deliberado em sua missão de escritor, ficcionista, poeta, dramaturgo, jornalista e político, rumo à construção da nação, da sua linguagem e da sua simbólica, garantes da consciência coletiva de um povo livre e diferenciado. Sua forte intuição política e estética fazia dele a consciência mais lúcida para perceber que uma nação

\footnotetext{
${ }^{2}$ La literatura indianista es creada por escritores no indigenas que pretenden ser portavoces de esa cultura. La literatura indigenista: los escritores tampoco son indigenas, pero buscan adentrarse en ese pensamiento desde su perspectiva, tratan de penetrar en su cosmología para dar a conocer esa cultura.

Literatura indígena es aquella producción escrita por los propios indígenas en su lengua original o en versión bilingüe. Puede abarcar todos los géneros: poesía, narrativa, teatro y ensayo (ROMERO apud DORRICO, 2018, p. 232).
} 
livre se constrói, sobretudo, por sua língua e sua literatura mediante amplos processos discursivos e criativos. Sua refinada percepção da nossa realidade em seu tempo fazia dele polemista destemido e cônscio do poder da palavra, instrumento especificador por excelência da humana condição e da nossa singularidade cultural: dimensões a interagir numa totalidade que se refaz incessantemente.

Nesse momento da literatura brasileira, o autor, por meio de suas produções artísticas, auxiliou na construção de uma unidade nacional. Portanto, para a análise proposta, será observada a construção da identidade indígena realizada na obra Iracema (1865) em contraposição à construção da identidade indígena realizada na obra A terra dos Mil povos (1998).

Nas palavras de Alencar, o trabalho dele e de autores do mesmo período deveria ser compreendido pela crítica da seguinte forma:

Sobretudo comprehendam os críticos a missão dos poetas, escriptores e artistas, nesse período especial e ambíguo da formação de uma nacionalidade. São estes os operários incumbidos de polir o talhe e as feições da individualidade que se vae esboçando no viver do povo (ALENCAR, 1998, p. 16).

Nesse momento histórico, Alencar se coloca como autor que esboçará a vivência do povo brasileiro:

Assim foi por toda a parte; assim ha de ser no Brazil. Vamos pois, nós, os- obreiros da fancaria, desbravando o campo, embora apupados pelos litteratos de rabicho. Tempo virá em que surjam os grandes escriptores para imprimir em nossa poesia o cunho do gênio brazileiro, e arrancando-lhe os andrajos coloniaes de que andam por ahi á vestir a bella estatua americana, a mostrem ao mundo, em sua magestosa nudez: náket majesly (ALENCAR, 1998, p. 17).

A construção de uma nacionalidade por meio das artes é um fenômeno a ser analisado e discutido no presente trabalho, pois mesmo sem ter como objetivo central de sua obra a construção de uma identidade brasileira, podemos analisar a construção da identidade indígena retratada nas obras de Alencar, tentando estabelecer um paralelo com a construção de identidade na obra de Jekupé.

Antes da análise propriamente dita, devemos ter uma visão geral de cada uma das obras. Nesse artigo, não é possível desenvolver um resumo extenso delas, mas, para o conhecimento geral, apresento uma breve síntese de cada obra. 
As REPRESENTAÇõES INDÍGENAS NOS LIVROS: A TERRA DOS MIL POVOS - HISTÓRIA INDÍGENA DO BRASIL CONTADA POR UM ÍNDIO, DE KAKÁ WERÁ JECUPÉ, E IRACEMA, DE JOSÉ DE ALENCAR

\section{IRACEMA}

O livro Iracema é a história de amor de Iracema, uma índia tabajara, e Martim, um colonizador português. Iracema é surpreendida por Martim enquanto estava repousando, ela se assusta e acaba atirando uma flecha nele que, por sua vez, não reage. Ele é recebido pelo Pajé, são levadas belas mulheres para ele, que recusa, e vai embora da tribo. Iracema vai atrás dele e pede para que volte, Martim aceita. O romance continua com batalhas que Martim precisa lutar e a gravidez de Iracema no fim do romance. Iracema deixa seu filho Moacir e acaba morrendo, devido à tristeza pelo afastamento de seu amor.

\section{A Terra do Mil Povos: História Indígena do Brasil contada Por Um Índio}

Publicado em 1998, é um livro no qual o autor aborda diversas temáticas relativas às questões indígenas, fazendo parte do Projeto Arapoty, uma campanha que busca um resgate da história e da cultura indígena. Dentre as temáticas abordadas, estão: o que é índio?; Tupã; A memória cultural; Guerra, guerreiros e escravos; dentre outros.

\section{ANÁlise Das ObRas}

O foco da análise será a representação do indígena nas duas obras. No livro Iracema, no capítulo II, há a descrição de Iracema:

Iracema, a virgem dos lábios de mel, que tinha os cabelos mais negros que a asa da graúna e mais longos que seu talhe de palmeira.

O favo da jati não era doce como seu sorriso; nem a baunilha recendia no bosque como seu hálito perfumado.

Mais rápida que a ema selvagem, a morena virgem corria o sertão e as matas do Ipu, onde campeava sua guerreira tribo, da grande nação tabajara. O pé grácil e nu, mal roçando, alisava apenas a verde pelúcia que vestia a terra com as primeiras águas (ALENCAR, 2009, p. 12).

Neste trecho da obra percebe-se a idealização e sexualização do corpo de Iracema: há sempre a comparação com algo natural, como aves, favo de mel, as árvores e plantas. A tentativa de relacionar a personagem Iracema à natureza brasileira busca inserir, na narrativa, elementos nativos, com o objetivo de incluir elementos nacionais para o texto.

Em outros momentos o autor também traz o nome de Tupã: "Nesse instante, como se o deus do trovão ouvisse as palavras de sua virgem, o antro, mudo em princípio, retroou surdamente. - Ouve! É a voz de Tupã." (ALENCAR, 2009, p. 47). O autor traz esses aspectos, 
principalmente a figura de Tupã e os rituais da tribo, para criar em seu texto o ambiente nacional, no intuito de moldar a literatura brasileira.

Pode-se afirmar que Alencar, em seu romance Iracema, inserir elementos nativos, no período em que a obra foi publicada, foi um avanço, uma vez que introduziu elementos da religião dos tabajaras, que é o deus Tupã. Trouxe, também, as características da personagem principal, que tem uma beleza única, é uma guerreira, porém é o olhar de um homem branco sobre a cultura indígena.

No livro A Terra do Mil Povos: História Indígena do Brasil contada por um índio, há uma parte dedicada a explicar o que é índio:

O índio não chamava nem chama a si mesmo de índio. O nome "índio" veio trazido pelos ventos dos mares do século XVI, mas o espírito "índio" habitava o Brasil antes mesmo de o tempo existir e se estendeu pelas Américas para, mais tarde, exprimir muitos nomes, difusores da Tradição do Sol, da Lua e do Sonho.

Então, o que índio, para o índio? Eu vou responder conforme me foi ensinado pelos meus avós, através do Ayvu Rapyta, passado de boca a boca com a responsabilidade do fogo sobre a noite estrelada, e através das cerimônias e encontros por que tenho passado com os ancestrais na terra e no Sonho.

Para aprender o conhecimento ancestral o índio passa por cerimônias, que são celebrações e iniciações para limpar a mente e para compreender o que nós chamamos de tradição, que é aprender a ler os ensinamentos registrados no movimento da natureza interna do Ser. O ensinamento da tradição começa sempre pelo nome das coisas e do modo pelo qual são nomeadas (JECUPÉ, 1998, p. 13).

Nessa parte do texto, pode-se verificar que o autor explica que o indígena não se denomina índio, que esse termo foi trazido pelos colonizadores, e também se verifica a questão cultural em que as tradições dos povos indígenas são passadas de geração em geração por meio de rituais, iniciações.

Outra questão importante para ser ressaltada é o que significa contar uma história para um indígena:

Ao contar a sua história, um índio, um clã, uma tribo parte do momento em que sua essência-espírito permeou a terra e relata a passagem dessa essência-espírito pelos reinos vegetal, mineral e animal. Há tribos que começam a sua história desde quando o clã eram seres do espírito das águas. Outras trazem a sua memória animal como início da história, assim como há aquelas que iniciam a sua história a partir da árvore que foram (JECUPÉ, 1998, p. 14). 
As REPRESENTAÇõES INDÍGENAS NOS LIVROS: A TERRA DOS MIL POVOS - HISTÓRIA INDÍGENA DO BRASIL CONTADA POR UM ÍNDIO, DE KAKÁ WERÁ JECUPÉ, E IRACEMA, DE JOSÉ DE ALENCAR

Esse trecho deixa explicito como é para o indígena narrar sua história: não é apenas criar uma narrativa, mas, sim, retornar aos seus ancestrais. As narrativas produzidas por indígenas carregam toda a essência-espírito de um povo.

A ligação entre os indígenas e a terra também é importante ser destacada, pois, segundo o autor:

Homens, árvores, serras, rios e mares são um copo, com ações interdependentes. Esse conceito só pode ser compreendido através do coração, ou seja, da natureza interna de cada um. Quando o humano das cidades petrificadas largarem as armas do intelecto, essa contribuição será compreendida. Nesse momento entraremos no Ciclo da Unicidade, e a Terra sem Males se manifestará no reino humano (JECUPÉ, 1998, p. 61).

Na cultura indígena há uma ligação direta com a natureza, como se percebe no trecho citado anteriormente, essa conexão é muito importante para os povos indígenas.

Com as análises realizadas, pode-se afirmar que José de Alencar insere elementos como o indígena e o deus Tupã, na tentativa de criar uma identidade nacional, o que foi importante para a literatura brasileira, mas não é o mesmo que a história narrada por um indígena.

A literatura indígena tem ganhado cada vez mais espaço. Em seu livro, Jecupé nos ensina o que é ser um indígena, como é profunda a ligação com a natureza e, principalmente, o que significa narrar suas histórias que carregam toda a ancestralidade de seus povos.

\section{Considerações FinaIs}

A partir das pesquisas realizadas, conclui-se que as representações dos indígenas nas duas obras são distintas. Na obra de José de Alencar, do século XIX, vemos a representação indígena pelo olhar do homem branco. Ele utiliza os elementos da natureza, para descrever Iracema, e também Tupã, para abordar as questões da religiosidade da tribo.

Por outro lado, na obra do século XX, Jecupé define o indígena como espírito, abordando também uma questão importante para a representação indígena que é a ligação com a natureza e que, quando um indígena conta sua história, retoma toda a ancestralidade, a cultura, as crenças de um povo.

Portanto, quando lemos uma narrativa produzida por um indígena, não podemos esquecer todo o significado que essa narrativa carrega, todo o contexto sócio-histórico-cultural.

Ainda há muito para ser estudado sobre literatura indígena, pois mesmo com os avanços alcançados, ainda há muito o que conquistar. Uma análise que acredito ser necessária futuramente é a análise de livros didáticos, uma vez que é imprescindível saber se há realmente a literatura indígena nos materiais didáticos das escolas públicas. Por isso, deixamos algumas 
reflexões a serem feitas: A lei 11.645/08 obriga o ensino de história e cultura afro-brasileira e indígena, mas os livros didáticos abordam a literatura indígena? Se sim, como ela é abordada nas unidades do livro? Como a comparação literária auxilia na construção da identidade literária dos estudantes?

\section{REFERÊNCIAS}

ALENCAR, J. Cartas sobre a Confederação dos Tamoios. Rio de Janeiro: Typographica Nacional do Diário, 1856.

ALENCAR, J. Iracema. São Paulo: Ciranda Cultural, 2009.

ALENCAR, J. Sonhos D’oro. 2. ed. São Paulo: Ática, 1998

BARDIN, L. Análise de conteúdo. Lisboa: Edições 70, 1977.

BRANDES, S. Diálogos interculturais na literatura indígena contemporânea: uma perspectiva bakhtiniana. 2017. 131f. Dissertação (Mestrado em Estudos da Linguagem) - Universidade Estadual de Ponta Grossa, Ponta Grossa, 2017.

BRASIL. Lei 11.645, de 10 de março de 2008. Torna obrigatório o ensino da temática História e Cultura Afro-Brasileira e Indígena. Disponível em: http://www.planalto.gov.br/ccivil_03/_ Ato2007-2010/2008/Lei/L11645.htm. Acesso em: 12 jul. 2020.

DORRICO, J. Vozes da literatura indígena brasileira contemporânea: do registro etnográfico à criação literária. In: DORRICO, J.; DANNER, L. F.; CORREIA, H. H. S.; DANNER, F. (org.). Literatura indígena brasileira contemporânea: criação, crítica e recepção. Porto Alegre: Editora Fi, 2018.

JECUPÉ, K. W. A Terra do Mil Povos: História Indígena do Brasil contada por um índio. São Paulo: Peirópolis, 1998.

LÜDKE, M.; ANDRÉ, M. E. D. A. Métodos de coleta de dados: observação, entrevista e análise documental In: LÜDKE, M.; ANDRÉ, M. E. D. A. Pesquisa em educação: abordagens qualitativas. São Paulo: EPU, 1986.

MAGALHÃES, D. J. G. Discurso sobre a história da literatura do brasil. Manifesto publicado na Revista Nictheroy em 1836. Ministério da Cultura: Fundação Biblioteca Nacional, 1836.

MENEZES, E. D. B. Alencar e seu projeto literário de construção nacional. Tensões Mundiais, v. 9, n. 16, p. 176-195, 18 out. 2018. 
AS REPRESENTAÇÕES INDÍGENAS NOS LIVROS: A TERRA DOS MIL POVOS - HISTÓRIA INDÍGENA DO BRASIL CONTADA POR UM ÍNDIO, DE KAKÁ WERÁ JECUPÉ, E IRACEMA, DE JOSÉ DE ALENCAR

PARANÁ. Resolução 3399, de 05 de agosto de 2010. Compõe as Equipes Multidisciplinares. Disponível em: https://www.legislacao.pr.gov.br/legislacao/pesquisarAto. do?action=exibir\&codAto=69167\&indice=1\&totalRegistros=1. Acesso em: 13 jul. 2020 .

Recebido para publicação em: 15 jul. 2020. Aceito para publicação em: 28 dez. 2020. 